\title{
Article \\ MicroRNA-511-3p Mediated Modulation of the Peroxisome Proliferator-Activated Receptor Gamma (PPAR $\gamma$ ) Controls LPS-Induced Inflammatory Responses in Human Monocyte Derived DCs
}

\author{
Dennis Awuah 1,2,*(D), Alisa Ruisinger ${ }^{1}$, Meshal Alobaid ${ }^{1,3}$, Chidimma Mbadugha ${ }^{1}$ \\ and Amir M. Ghaemmaghami ${ }^{1,4, *}$ \\ 1 Immunology and Immuno-Bioengineering Group, School of Life Sciences, Faculty of Medicine and Health \\ Sciences, University of Nottingham, Nottingham NG7 2RD, UK; alisa-ru@gmx.de (A.R.); \\ m.alobaid@aiu.edu.kw (M.A.); mbadugha.chidimma@gmail.com (C.M.) \\ 2 T Cell Therapeutics Research Laboratory, Beckman Research Institute, City of Hope, Duarte, CA 91010, USA \\ 3 Immunology and Allergy, American International University, Al-Jahra 00003, Kuwait \\ 4 Terasaki Institute for Biomedical Innovation, Los Angeles, CA 90024, USA \\ * Correspondence: dawuah@coh.org (D.A.); Amir.ghaemmaghami@nottingham.ac.uk (A.M.G.)
}

check for updates

Citation: Awuah, D.; Ruisinger, A.; Alobaid, M.; Mbadugha, C.; Ghaemmaghami, A.M.

MicroRNA-511-3p Mediated Modulation of the Peroxisome Proliferator-Activated Receptor Gamma (PPAR $\gamma$ ) Controls LPS-Induced Inflammatory Responses in Human Monocyte Derived DCs. Immuno 2022, 2 , 104-117. https://doi.org/10.3390/ immuno2010008

Academic Editor: Young-Su Yi

Received: 1 December 2021

Accepted: 11 January 2022

Published: 14 January 2022

Publisher's Note: MDPI stays neutral with regard to jurisdictional claims in published maps and institutional affiliations.

Copyright: (c) 2022 by the authors. Licensee MDPI, Basel, Switzerland. This article is an open access article distributed under the terms and conditions of the Creative Commons Attribution (CC BY) license (https:// creativecommons.org/licenses/by/ $4.0 /)$.

\begin{abstract}
The peroxisome proliferator-activated receptor gamma (PPAR $\gamma$ ) is a ligand-activated transcription factor expressed in dendritic cells (DCs), where it exerts anti-inflammatory responses against TLR4-induced inflammation. Recently, microRNA-511 (miR-511) has also emerged as a key player in controlling TLR4-mediated signalling and in regulating the function of DCs. Interestingly, PPAR $\gamma$ has been previously highlighted as a putative target of miR-511 activity; however, the link between miR-511 and PPAR $\gamma$ and its influence on human DC function within the context of LPSinduced inflammatory responses is unknown. Using a selection of miR-511-3p-specific inhibitors and mimics, we demonstrate for the first time that knockdown or overexpression of miR-511-3p inversely correlates with PPAR $\gamma$ mRNA levels and affects its transcriptional activity following treatment with rosiglitazone (RSG; PPAR $\gamma$ agonist), in the presence or absence of LPS. Additionally, we show that PPAR $\gamma$-mediated suppression of DC activation and pro-inflammatory cytokine production in miR-511-3p knockdown DCs is abrogated following overexpression of miR-511-3p. Lastly, PPAR $\gamma$ activation suppressed LPS-mediated induction of indoleamine 2,3-dioxygenase (IDO) activity in DCs, most likely due to changes in miR-511-3p expression. Our data thus suggests that PPAR $\gamma$-induced modulation of DC phenotype and function is influenced by miR-511-3p expression, which may serve as a potential therapeutic target against inflammatory diseases.
\end{abstract}

Keywords: dendritic cells; miR-511-3p; RNAi; PPAR $\gamma$; inflammation; indoleamine 2,3 dioxygenase; immune modulation

\section{Introduction}

The innate immune system rapidly responds to endotoxin exposure through the induction of acute inflammatory responses [1]. Endotoxins such as LPS, a major cell wall component of Gram-negative bacteria, can induce potent inflammatory responses through the release of an array of mediators such as cytokines, chemokines, and growth factors. However, when uncontrolled, inflammatory responses can lead to tissue damage and chronic inflammatory diseases [2]. Dendritic cells (DCs) are the most efficient antigenpresenting cells (APCs) capable of initiating and maintaining primary immune responses and are key players in regulating inflammatory responses [3]. DCs are highly sensitive to even low concentrations of LPS in the environment and detect the presence of LPS (for instance, during bacterial infection) via Toll-like receptor 4 (TLR4). This triggers 
downstream signalling pathways, which coordinate the expression of genes required to initiate or control inflammation [4].

Recently, the role of the peroxisome proliferator-activated receptor $\gamma$ (PPAR $\gamma)$ in modulating inflammatory responses has been of particular interest. PPAR $\gamma$ is a lipid-activated transcription factor expressed in a variety of cell types, including DCs, where it regulates genes associated with adipogenesis, lipid metabolism and inflammation [5]. In DCs, PPAR $\gamma$ regulates other cellular processes, including maturation and migration, activation, antigen presentation and cytokine production [6-8]. Moreover, PPAR $\gamma$ activation in DCs in the presence of LPS resulted in decreased IL-12 expression [9], suggesting that PPAR $\gamma$ ligands may promote anti-inflammatory responses. Studies by us and others have also demonstrated a key role for the tryptophan-metabolising enzyme IDO in controlling LPS-mediated inflammatory responses [10-13]. Interestingly, the recent finding that PPAR $\gamma$ promotes IDO activity and subsequent immune suppression in the tumour microenvironment highlights the complexity of PPAR $\gamma$-induced regulatory mechanisms [14]. Nevertheless, the overall immunosuppressive effect of PPAR $\gamma$ and the underlying mechanisms, particularly during LPS-induced inflammation in DCs, are not fully understood.

MicroRNAs (miRNAs) are a class of gene regulators that bind the $3^{\prime}$ UTR of target genes and cause translational inhibition or mRNA degradation [15]. Due to their role in regulating biological processes, miRNAs represent crucial regulators in human health and disease. Recently, miR-511-3p, the functional miRNA of the mature miR-511 strand (located at the 3 end of miR-511), has been identified as an important regulator of human DC and macrophage development and function. For example, miR-511-3p expression is increased following DC differentiation from monocytes [16] and has been shown to be a key regulator of TLR4 expression in DCs [17]. Additionally, transcriptional products associated with inflammation and wound healing in alternatively activated macrophages (AAMs) were found to be altered by miR-511 expression [18]. Recently, miR-511-3p has been shown to suppress cockroach allergen-induced airway hyperresponsiveness and lung inflammation in mice. Interestingly, PPAR $\gamma$ has also been highlighted as a putative target of miR-511 activity, affecting human myeloid cell differentiation and function [17,19]. Here, we sought to investigate the potential relationship between miR-511-3p expression and $\operatorname{PPAR} \gamma$ activity and how this influences LPS-mediated inflammatory responses in human DCs. Better understanding of the mechanisms regulating PPAR $\gamma$ activity could pave the way for the rational design of therapies against inflammatory disorders.

\section{Materials and Methods}

\subsection{Generation of Monocyte-Derived Dendritic Cells (DCs)}

This was done as previously described [20,21]. Buffy coats were obtained from healthy donors (National Blood Service, Sheffield, UK) after obtaining informed written consent and following ethics committee approval (Research Ethics Committee, Faculty of Medicine and Health Sciences, University of Nottingham; BT08052013-160-1701). PBMCs were separated by density gradient centrifugation on Histopaque (Sigma-Aldrich, Dorset, UK), and monocytes were purified by positive selection using the MACS CD14 isolation kit (Miltenyi Biotec, Woking, UK). Briefly, PBMCs were washed twice with MACS buffer ( $2 \mathrm{mM}$ EDTA with $0.5 \%$ FBS in PBS) and incubated with CD14 ${ }^{+}$magnetic beads for $15 \mathrm{~min}$ at $4{ }^{\circ} \mathrm{C}$. Subsequently, labelled cells were allowed to bind to LS columns (Miltenyi Biotec), washed three times with MACS buffer before eluting positively bound fraction. Monocytes were then cultured in 24-well plates using RPMI medium supplemented with $10 \%$ heatinactivated FBS, $100 \mathrm{U} / \mathrm{mL}$ penicillin, $100 \mathrm{U} / \mathrm{mL}$ streptomycin and $2 \mathrm{mM}$ L-glutamine (all from Sigma). Cells were incubated at $37^{\circ} \mathrm{C}$ with $5 \% \mathrm{CO}_{2}$ in a humidified incubator. The purity of CD14 $4^{+}$cells was always above $90 \%$, as measured by flow cytometry. DC differentiation was carried out over 6 days with $250 \mathrm{U} / \mathrm{mL}$ IL-4 and $50 \mathrm{ng} / \mathrm{mL}$ GM-CSF (Miltenyi Biotec). 


\subsection{Flow Cytometry Analysis}

Mouse monoclonal antibodies against human CD86 (clone FM95) and DC-SIGN (clone DCN47.5) were purchased from Miltenyi Biotec. Antibodies against human CD83 (clone HB15e) was purchased from eBioscience, Hartfield, UK. Anti-PDL1 (clone MIH1) antibody was purchased from BD Biosciences (San Jose, CA, USA), and the anti-CD206 antibody (clone 15-2) was purchased from Biolegend (San Diego, CA, USA). Briefly, cells were collected and washed twice in cold PBA (PBS buffer containing $0.5 \%$ BSA and $0.1 \%$ sodium azide (Sigma Aldrich)). Staining with labelled antibodies was then carried out in the dark at $4{ }^{\circ} \mathrm{C}$ for $20 \mathrm{~min}$ according to the manufacturer's instructions. Unless otherwise stated, specific antibodies were conjugated to Fluorescein Isothiocyanate (FITC), Phycoerythrin (PE) or Phycoerythrin Cyanine 5.1 (PE/Cy5). Following staining, samples were washed twice with PBA buffer and fixed in $0.5 \%$ formaldehyde solution before analysis. Nonreactive, isotype-matched antibodies were used as controls. Flow cytometry was carried out on the FC500 Flow Cytometer (Beckman Coulter, London, UK), and data were analysed using Weasel Software for Windows.

\subsection{Quantification of IDO Activity}

IDO activity was determined as described before [20,22]. Briefly, DCs $\left(2.5 \times 10^{5}\right.$ cells $\left./ \mathrm{mL}\right)$ were seeded in a 24-well plate with complete RPMI media, supplemented with $100 \mu \mathrm{M}$ L-tryptophan (TRP) (Sigma Aldrich). Cells were then stimulated with PPAR $\gamma$ agonist and antagonist RSG and GW9662 $(5 \mu \mathrm{M})$, respectively, for $24 \mathrm{~h}$, in the presence and absence of LPS $(0.1 \mu \mathrm{g} / \mathrm{mL})$ and culture supernatant was harvested and stored at $-20{ }^{\circ} \mathrm{C}$ until analysis. A colourimetric assay for IDO activity was performed by measuring the levels of L-kynurenine (KYN) produced in culture supernatant. The concentration of L-KYN was then calculated from a standard curve of defined concentrations from 0 to $200 \mu \mathrm{M}$. Rosiglitazone (RSG) and GW9662 were purchased from Cayman chemicals (Cambridge, UK), and L-KYN was obtained from Sigma Aldrich, UK.

\subsection{Live/Dead Assay}

Cell viability following treatment with RSG and GW9662 was determined using the LIVE/DEAD assay kit (Thermo Fisher Scientific, Leicester, UK) as described previously [23]. Cells were imaged using the Etaluma LS720 Microscope (Carlsbad, CA, USA). Data were analysed using Image J software v1.51 for Windows.

\subsection{RNA Interference}

Pre-designed miR-511-3p inhibitors and mimics were purchased from Qiagen, and transfection was carried out using the HiPerFect Transfection Reagent according to the manufacturer's protocol (Qiagen). The miRNA targeted sequence was 5'-AAUGUGUAGCAAAAGACAGA-3' ${ }^{\prime}$. Briefly, CD14 $4^{+}$monocytes were suspended in Opti-MEM ${ }^{\circledR}$ reduced serum media (Gibco) and seeded. Prior to transfection, miR-511-3p inhibitor or mimic was diluted in serum-free media with transfection reagent in separate tubes for $10 \mathrm{~min}$ at room temperature before adding dropwise unto cells. The miScript Inhibitor Negative Control and the AllStars Negative Control siRNA (Qiagen) were used as scrambled controls (CT) for inhibitors and mimics, respectively. All transfections were carried out at a final concentration of $50 \mathrm{nM}$, as determined during optimisations. Monocytes were differentiated into DCs after 6 h of incubation, with fresh Opti-MEM ${ }^{\circledR}$ media supplemented with IL-4 and GM-CSF. Transfection efficiency was determined using the fluorescently labelled siGLO RISC-free control siRNA (GE Healthcare, Chicago, IL, USA), and miRNA and/or mRNA expression was assessed afterwards.

\subsection{RNA Isolation and cDNA Synthesis}

Dendritic cells treated with miR-511-3p inhibitors and mimics as well as controls were stimulated on day 6 with RSG in the presence or absence of LPS (Sigma Aldrich) for $24 \mathrm{~h}$ before harvesting. Cell samples were then washed twice with cold PBS and stored in 
RNA later before RNA isolation. Total RNA, including small RNAs, was isolated with Trizol Reagent using the miRNeasy Mini kit, according to the manufacturer's instructions (Qiagen). The concentration of purified RNA was measured using a NanoDrop 1000 spectrophotometer (Thermo Fisher Scientific, Leicester, UK). First-strand cDNA was then generated with the SuperScript III Reverse Transcription kit (Thermo Fisher Scientific, Leicester, UK) or the miScript Reverse Transcription (RT) II kit (Qiagen) according to the manufacturer's instructions. Reverse transcription was done with the T100 Thermal Cycler (Bio-Rad, Watford, UK) and the 5X HiFlex buffer was used for parallel qRT-PCR quantification of mature miRNA and mRNA.

\subsection{Real Time PCR (qRT-PCR)}

Comparative real-time PCR for miR-511-3p expression was carried out on the MxPro 3005P qRT-PCR system (Stratagene, CA, USA) using the miScript SYBR Green PCR kit (Qiagen) according to the manufacturer's instructions. Briefly, 12.5 $\mu \mathrm{L}$ 2X QuantiTect SYBRGreen Master Mix, 2.5 $\mu \mathrm{L}$ 10X Universal Primer and $2.5 \mu \mathrm{L}$ Primer Assay (forward primer) was mixed with 3 ng of reverse transcription product. qRT-PCR cycling was initiated at $95^{\circ} \mathrm{C}$ for $15 \mathrm{~min}$, followed by 40 cycles of $94^{\circ} \mathrm{C}$ for $15 \mathrm{~s}, 55^{\circ} \mathrm{C}$ for $30 \mathrm{~s}$ and $70{ }^{\circ} \mathrm{C}$ for $30 \mathrm{~s}$. Mature miR-511-3p-specific primers were obtained from Qiagen, and relative expression was normalised to U6 (RNU6-2) small nuclear RNAs. qRT-PCR for mRNA expression was done with the Brilliant III Ultra-Fast SYBR Green qRT-PCR Master Mix (Agilent Technologies, Santa Clara, CA, USA), as previously described [20]. The two-step cycling reaction was initiated at $95^{\circ} \mathrm{C}$ for $3 \mathrm{~min}$ followed by 40 cycles of $95^{\circ} \mathrm{C}$ for $20 \mathrm{~s}$ and $60^{\circ} \mathrm{C}$ for $20 \mathrm{~s}$. PPARG and FABP4 mRNA expression levels were normalised GAPDH and calculated using the comparative Delta $\mathrm{Ct}$ method, which determines the difference in $\mathrm{Ct}$ values between the gene of interest and the housekeeping gene. All experimental procedures were done in triplicate. Forward and reverse mRNA primers were selected using Roche Universal Probes Library and purchased from Eurofins Scientific, Wolverhampton, UK (Table 1).

Table 1. Primers for real-time PCR.

\begin{tabular}{ccc}
\hline Genes & Primer2 & Sequence $\left(\mathbf{5}^{\prime} \mathbf{- 3}^{\prime} \mathbf{)}\right.$ \\
\hline \multirow{2}{*}{ GAPDH } & Forward & GAGTCAACGGATTTGGTCGT \\
& Reverse & GACAAGCTTCCCGTTCTCAG \\
PPARG & Forward & TGTGAAGCCCATTGAAGACA \\
& Reverse & ACTCAGGGTGGTTCAGCTTC \\
FABP4 & Forward & GGATGGAAAATCAACCACCA \\
& Reverse & GGAAGTGACGCCTTTCATGA \\
\hline
\end{tabular}

\subsection{Cytokine ELISA}

Culture supernatants were collected and stored at $-20{ }^{\circ} \mathrm{C}$ before analysis. The levels of TNF- $\alpha$, IL-10 and IL-6 were measured by sandwich ELISA using the Duo Set ELISA kit (R\&D Systems, Abingdon, UK) [24] according to manufacturer's instructions.

\subsection{Statistical Analysis}

Data were analysed using GraphPad Prism v7.02 for Windows (GraphPad Software, San Diego, CA, USA) and values expressed as mean \pm standard deviation (SD) from three independent experiments unless otherwise stated. Statistical differences were determined using Student's $t$-test (to compare two groups) or one/two-way ANOVA (to compare three or more groups) with Tukey's post-hoc testing. A $p$-value $<0.05$ was considered statistically significant. 


\section{Results}

3.1. Changes in miR-511-3p Expression Affect PPAR $\gamma$ Expression and Activity in Human DCs

We first examined PPAR $\gamma$ regulation in human DCs after changes in miR-511-3p expression. For this purpose, we differentiated monocyte-derived DCs in the presence of miR-511-3p-specific inhibitors and mimics, which resulted in a significant downregulation and/or increase in miR-511-3p miRNA expression, respectively (Figure 1). Subsequently, we measured the expression of PPAR $\gamma$ by comparative qRT-PCR and showed for the first time that knockdown of miR-511-3p (henceforth referred to as miR-511-3p-inhibitor), resulted in a significant increase in PPAR $\gamma$ mRNA levels (Figure 1A), whereas a significant decrease in PPAR $\gamma$ expression was observed in miR-511-3p overexpressed cells (i.e., miR-511-3p-mimic) (Figure 1B). As demonstrated in Figure 1C, there is a strong inverse association between the level of PPAR $\gamma$ relative to miR-511-3p, indicated by an increase in PPAR $\gamma$ expression when miR-511-3p is low, and vice versa when miR-511-3p expression is high. It is important to note that transfection with either miR-511-3p inhibitors or mimics did not result in loss of cell viability, as determined by Annexin-V staining (Figure S1), and did not impact monocyte-to-DC differentiation, as we have previously demonstrated [16].

\section{A}

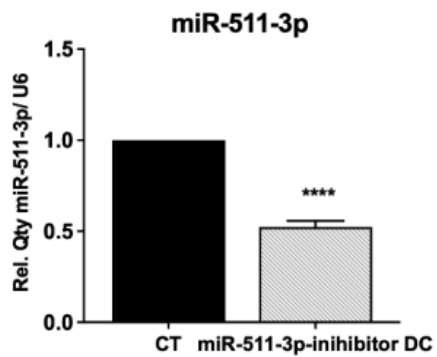

B
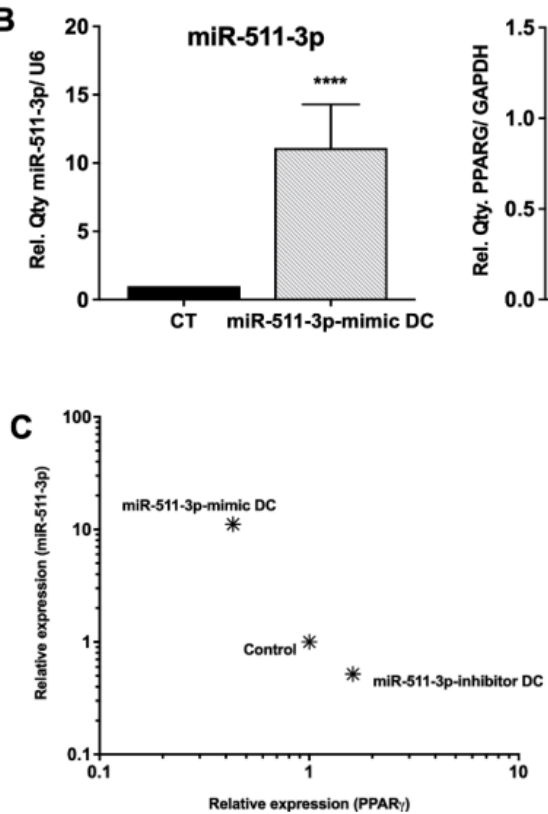

PPAR $\gamma$
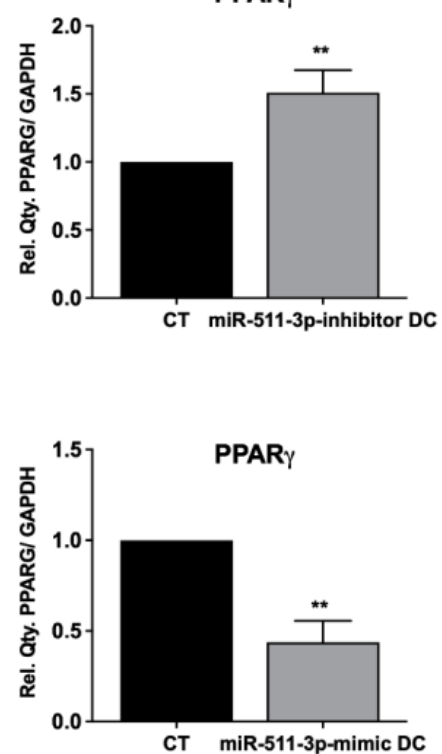

CT miR-511-3p-mimic DC

Figure 1. Analysis of PPAR $\gamma$ mRNA levels in response to up- or downregulation of miR-511-3p expression. Relative expression of miR-511-3p and PPAR $\gamma$, respectively, in (A) miR-511-3p-inhibitor and (B) miR-511-3p-mimic DCs. (C) Scatter plot showing the relationship between miR-511-3p and PPAR $\gamma$ expression. Monocytes were differentiated in the presence of $50 \mathrm{nM}$ miR-511-3p-specific inhibitors and mimics. Gene expression was assessed on day 6 and normalised to U6 and GAPDH for miRNA and mRNA, respectively. (One representative data is shown out of three). ${ }^{* *} p<0.01$, $* * * * p<0.0001$. 
Several natural (e.g., 15d-PGJ ${ }_{2}$ ) as well as synthetic agonists (also known as thiazolidinediones (TZDs)) have been shown to induce PPAR $\gamma$ activation in a variety of cell types $[25,26]$. Following up- or downregulation of miR-511-3p and its effect on PPAR $\gamma$ expression, we treated DCs with LPS and the synthetic agonist rosiglitazone (RSG) in order to determine the influence of these ligands on PPAR $\gamma$ activity. PPAR $\gamma$ activity was assessed by measuring the expression of one of its target genes (i.e., FABP4) by qRT-PCR. Interestingly, we found that PPAR $\gamma$ activity was downregulated in control and miR-511-3p-inhibitor DCs following LPS treatment but was significantly increased after RSG stimulation alone and in the presence of LPS (LPS + RSG) (Figure 2A), suggesting that lack of miR-511-3p expression promotes the effects of PPAR $\gamma$ activity in DCs. In line with this, PPAR $\gamma$ mRNA expression was also downregulated in miR-511-3p-inhibitor DCs following LPS treatment (data not shown). In contrast, we found a decrease in PPAR $\gamma$ activity in miR-511-3p-mimic DCs treated with LPS + RSG, highlighting the immune regulatory control of miR-511-3p overexpression on PPAR $\gamma$ activity (Figure 2B).
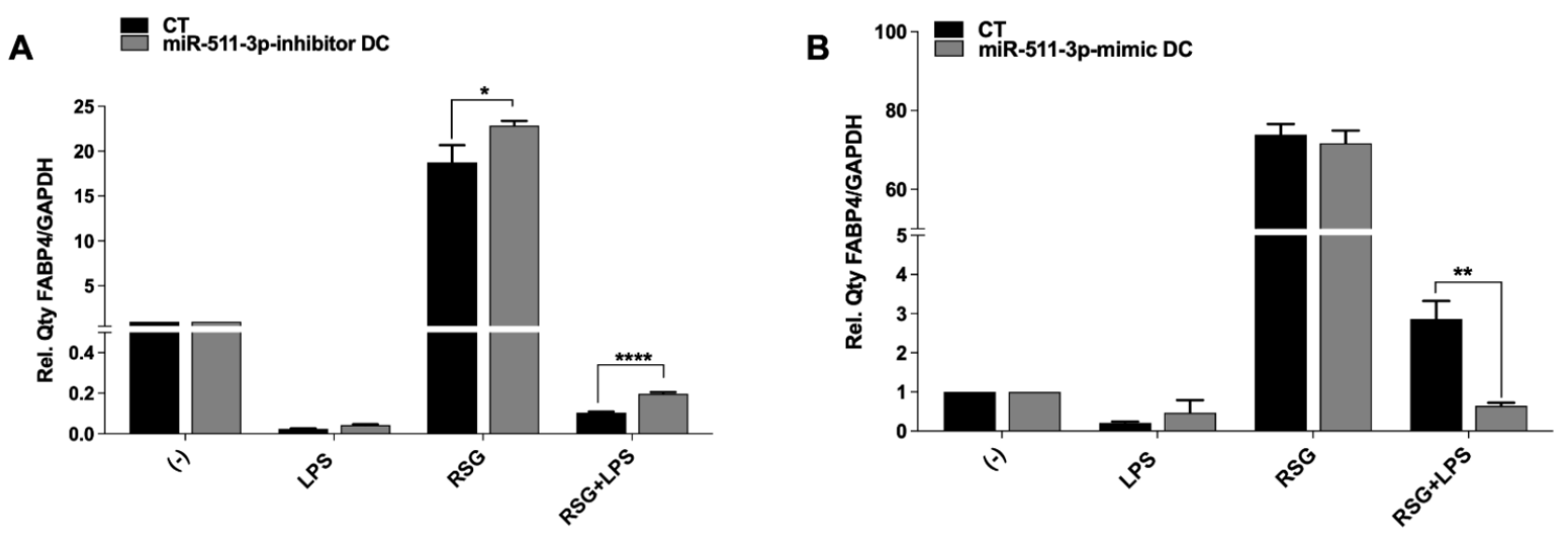

Figure 2. PPAR $\gamma$ activity is affected by changes in miR-511-3p expression. Relative FABP4 expression in (A) miR-511-3p-inhibitor and (B) miR-511-3p-mimic DCs treated with RSG and LPS. Monocytederived DCs were transfected with $50 \mathrm{nM}$ inhibitor and mimic for 6 days and stimulated with $5 \mathrm{uM}$ RSG and $0.1 \mathrm{ug} / \mathrm{mL}$ LPS for $24 \mathrm{~h}$. Gene expression was normalised to GAPDH. (One representative experiment out of three). ${ }^{*} p<0.05,{ }^{* *} p<0.01,{ }^{* * *} p<0.0001$.

Studies indicate that RSG treatment affects DC maturation and downstream activation [27]. In line with this, we found that RSG-downregulated LPS induced the expression of the CD83 maturation marker but not CD86 in untransfected DCs. Moreover, there were no changes to the expression of mannose receptor (MR) as well as PDL-1, with the exception of DC-SIGN, which was significantly upregulated following LPS-induced DC maturation (Figure 3A). As expected, miR-511-3p-inhibitor DCs downregulated CD83 expression following LPS stimulation in the presence of RSG (LPS/RSG) but was rescued following the addition of GW9662. Conversely, CD83 expression in miR-511-3p-mimic DCs after LPS treatment remained unchanged either in the presence of RSG or its antagonist GW9662, which is indicative of suppression of PPAR $\gamma$ activity by miR-511-3p-mimic cells (Figure 3B). Although LPS-induced CD86 expression was not affected in the miR-511$3 p$-inhibitor cells after PPAR $\gamma$ stimulation with RSG, we observed a decrease in CD86 expression following the addition of GW9662 (Figure 3C). Taken together, our data support the notion that increased miR-511-3p expression could downregulate PPAR $\gamma$ activity and promote LPS-induced DC maturation and activation. 

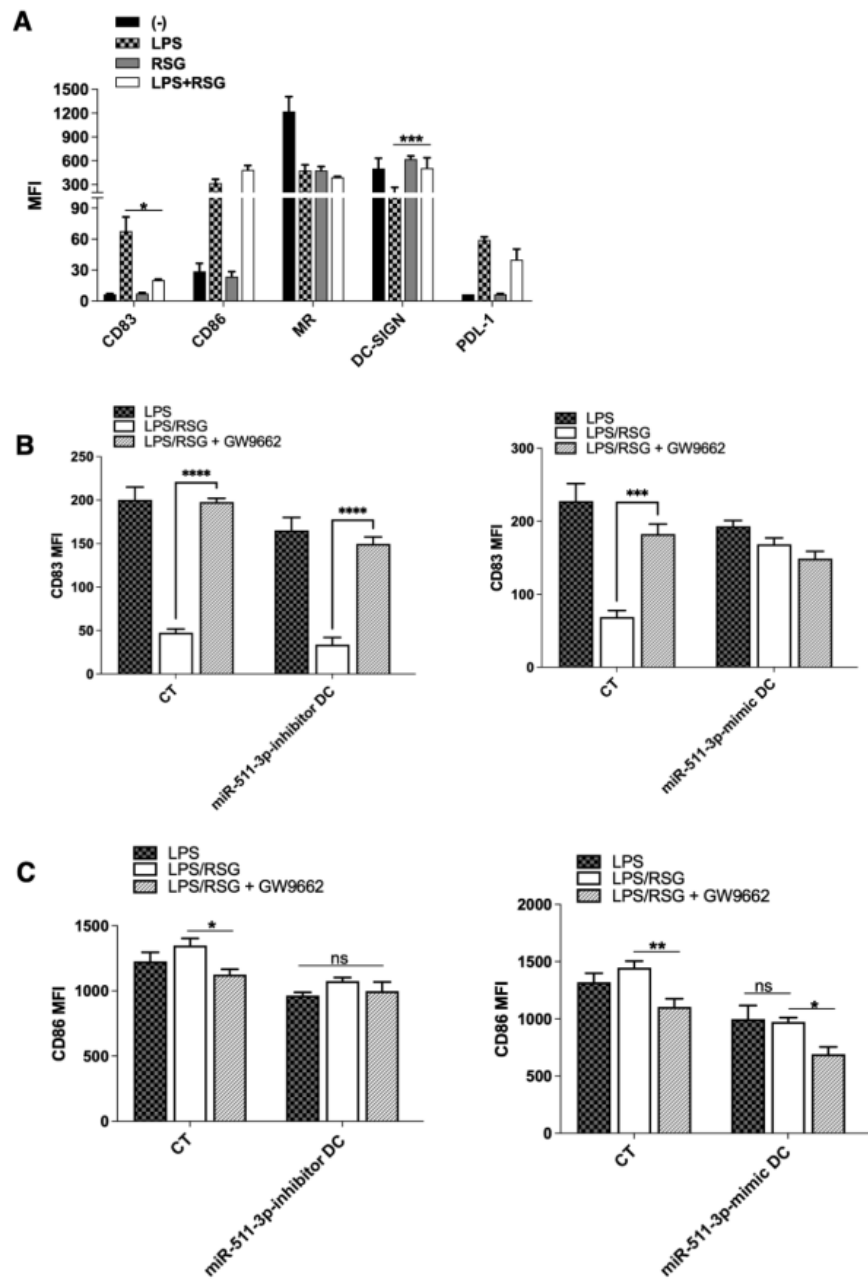

Figure 3. LPS-induced DC maturation and activation is affected by PPAR $\gamma$ activity. (A) Flow cytometry analysis of human DC maturation, activation and exhaustion markers (CD83, CD86 and PDL-1) following treatment with LPS and RSG. Receptors for antigen capture, including MR and DC-SIGN, are also shown $(n=4)$. (B,C) MFI ratios for CD83 and CD86, respectively, in human miR511-3p-inhibitor and miR-511-3p-mimic DCs. Monocyte-derived DCs were transfected with $50 \mathrm{nM}$ miRNA inhibitor and mimic and stimulated with $0.1 \mu \mathrm{g} / \mathrm{mL}$ LPS and $5 \mu \mathrm{M}$ RSG in the presence or absence of $5 \mu \mathrm{M}$ GW9662 for $24 \mathrm{~h}(n=3) .{ }^{*} p<0.05,{ }^{* *} p<0.01,{ }^{* * *} p<0.001,{ }^{* * * *} p<0.0001$.

\subsection{PPAR $\gamma$ Activation Modulates Cytokine Production in miR-511-3p-Transfected DCs}

It has been previously described that PPAR $\gamma$ activation is able to modulate LPSinduced cytokine production in cells such as macrophages and DCs from humans and mice [28-30]. Having demonstrated the influence of miR-511-3p expression on PPAR $\gamma$ activity in human DCs, we examined the levels of IL-6 and IL-10, cytokines produced by miR-511-3p-inhibitor and miR-511-3p-mimic DCs in culture supernatant. miR-511-3pinhibitor and miR-511-3p-mimic DCs were treated with RSG, LPS or both for $24 \mathrm{~h}$ in the presence or absence of PPAR $\gamma$ antagonist GW9662. As shown in Figure 4, IL-6 production in miR-511-3p-inhibitor DCs was significantly downregulated in LPS/RSG conditions compared to LPS alone; however, in the presence of the PPAR $\gamma$ antagonist GW9662, IL-6 was significantly increased, abrogating the suppressive influence of RSG in these conditions (Figure 4A). In untransfected DCs, we found no significant changes in RSG-mediated suppression of IL- 6 and TNF- $\alpha$ production (induced by LPS treatment) following treatment with GW9662 (Figure S2). Conversely, miR-511-3p-mimic DCs showed a significant increase in IL-6 after LPS treatment alone and in the presence of RSG but not after GW9662 treatment. The downregulation in PPAR $\gamma$ expression and activity resulting from miR511-3p overexpression could account for an increase in IL-6 production, suggesting that 
$\operatorname{PPAR} \gamma$ is a potent suppressor of LPS-induced pro-inflammatory responses. Interestingly, the production of IL-10 was increased in all conditions following knockdown of miR-511-3p (i.e., miR-511-3p-inhibitor DCs) compared to CT, with the exception of LPS/RSG condition, which showed no statistically significant difference with CT samples (Figure 4B). As expected, miR-511-3p-mimic DCs downregulated IL-10 production following treatment with LPS in the presence or absence of RSG, compared to scrambled controls (CT), whereas no significant changes were seen in IL-10 secretion between LPS alone or LPS/RSG conditions.

A
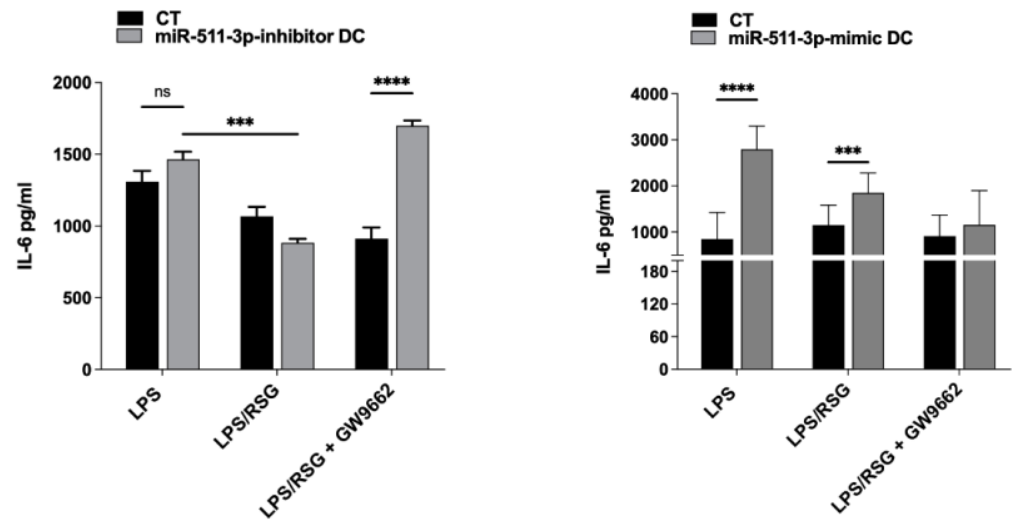

B
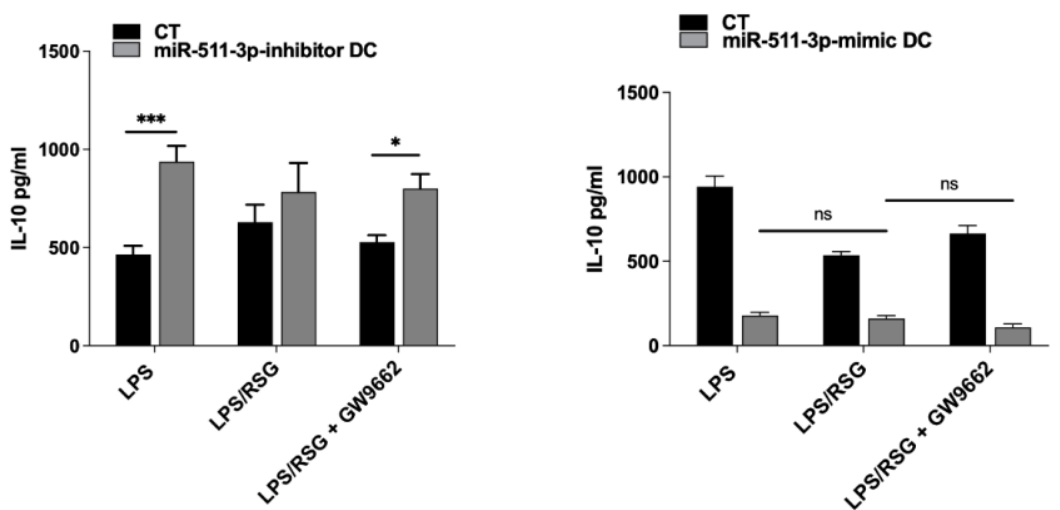

Figure 4. Cytokine secretion is modulated by PPAR $\gamma$ activity in miR-511-3p transfected DCs. (A) IL-6 pro- and (B) IL-10 anti-inflammatory cytokine production by miR-511-3p-inhibitor and miR-511-3pmimic DCs, respectively, stimulated with $5 \mu \mathrm{M}$ RSG and $0.1 \mu \mathrm{g} / \mathrm{mL}$ LPS for $24 \mathrm{~h}$ in the presence or absence of $5 \mu \mathrm{M}$ GW9662. Culture supernatants were collected, and cytokine levels were quantified by $\operatorname{ELISA}(n=3) .{ }^{*} p<0.05,{ }^{* * *} p<0.001,{ }^{* * * *} p<0.0001$, ns: not significant.

\subsection{PPAR $\gamma$ Modulation of LPS-Induced IDO Activity Is Influenced by miR-511-3p Expression in} Human DCs

Under steady-state conditions, induction of the tryptophan-metabolising pathway by IDO acts as an immune regulatory mechanism in response to pro-inflammatory stimuli such as IFN- $\gamma$ and TNF- $\alpha[31,32]$. Under certain conditions, IDO induction can also be mediated through an IFN- $\gamma$-independent pathway, such as the presence of LPS during bacterial infection $[10,33]$. Recently, PPAR $\gamma$ was also shown to promote IDO activity and generation of local tolerogenic DCs within solid tumours [14]; nonetheless, the relationship between PPAR $\gamma$ and IDO in DCs within the context of LPS-induced inflammation is unknown. In order to investigate this, we first treated untransfected DCs with LPS, RSG and GW9662 alone to determine the influence of these ligands on IDO activity (Figure S3). Subsequently, we determined IDO activity following treatment with LPS in the presence or absence of these ligands. IDO activity was measured by colourimetric determination of kynurenine (KYN) produced in culture supernatant. As summarised in Figure 5, RSG alone had no influence on IDO activity but significantly downregulated LPS-induced IDO activity in DCs. 
Additionally, there were no significant changes to IDO activity following the addition of the PPAR $\gamma$ antagonist (LPS/RSG + GW9662) (Figure 5A). Next, we examined whether changes in miR-511-3p expression in DCs could affect IDO activity following treatment with LPS and RSG. Again, RSG stimulation alone had no effect on IDO activity (data not shown) but was able to significantly downregulate LPS-induced IDO activity in miR-511-3p-inhibitor DCs (Figure 5B). Interestingly, IDO activity was markedly reduced in the miR-511-3p-mimic cells after treatment with LPS and LPS/RSG, similar to observations with IL-10, suggesting that IDO activity in DC could be potentially regulated by miR-511-3p in a PPAR $\gamma$-independent fashion. Furthermore, we found an inverse correlation between miR-511-3p regulation and IDO activity after treatment with GW9662, indicating that PPAR $\gamma$ may play a key role in IDO downregulation induced by RSG in human DCs (Figure 5C). These data suggest that PPAR $\gamma$ activation is able to downregulate IDO activity in human DCs partly due to changes in miR-511-3p expression. As indicated in the LIVE/DEAD stain, DC viability was comparable in all conditions tested (Figure S4).

A

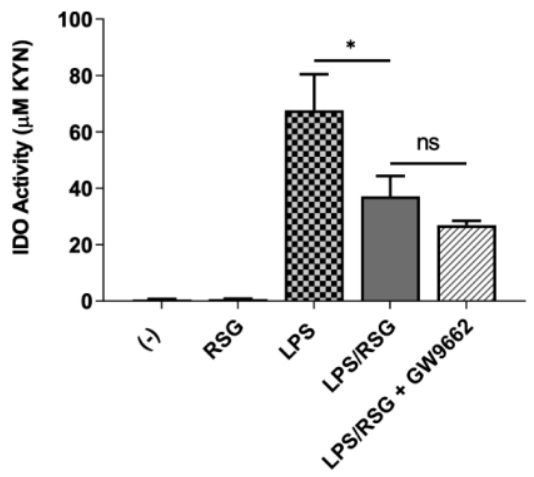

B

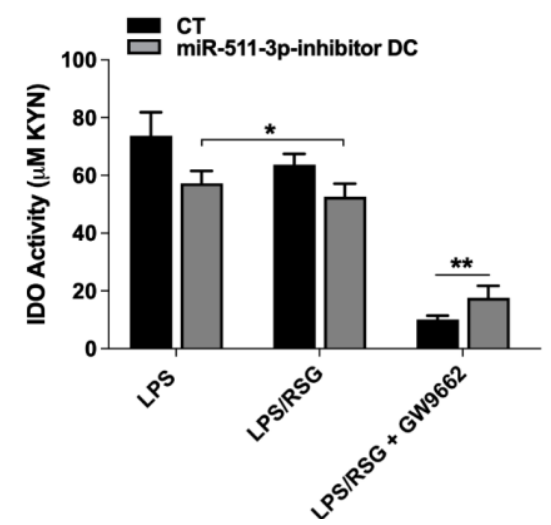

C

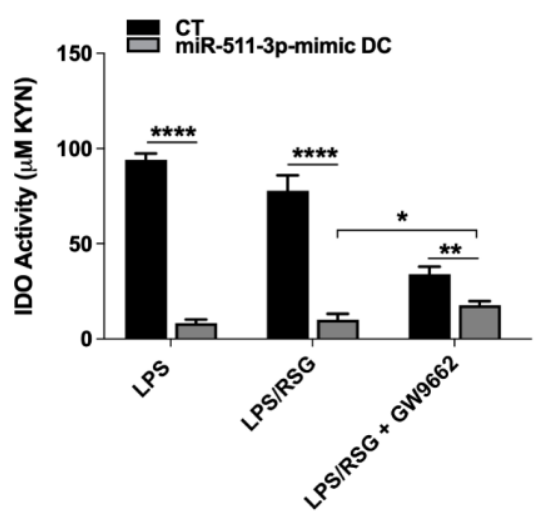

Figure 5. IDO regulation by human monocyte-derived dendritic cells. (A) IDO activity in human DCs treated with $5 \mu \mathrm{M}$ RSG and $0.1 \mu \mathrm{g} / \mathrm{mL}$ LPS for $24 \mathrm{~h}$ in the presence or absence of $5 \mu \mathrm{M}$ GW9662 $(n=3)$. (B,C) IDO activity in miR-511-3p-inhibitor and miR-511-3p-mimic DCs, respectively, following treatment with $5 \mu \mathrm{M}$ RSG and $0.1 \mu \mathrm{g} / \mathrm{mL}$ LPS for $24 \mathrm{~h}$ in the presence or absence of $5 \mu \mathrm{M}$ GW9662. Culture supernatant was collected and examined for IDO activity $(n=3)$. ${ }^{*} p<0.05,{ }^{* *} p<0.01$, **** $p<0.0001$, ns: not significant.

\section{Discussion}

The PPAR receptors, which belong to the nuclear hormone receptor superfamily, were originally identified as key players in controlling the oxidation of lipids and fatty acids. Among the three members, PPAR $\gamma$ is essential for controlling adipocyte differentiation and glucose metabolism [34], and, presently, several reports have demonstrated the importance of PPAR $\gamma$ agonists as treatment against inflammatory diseases [35-37]. MicroRNAs are 
crucial players in mammalian gene regulation and their role in fine-tuning gene expression, particularly through dysregulated expression, has been reported in several infectious and inflammatory diseases. In this study, the role of miR-511-3p in modulating PPAR $\gamma$ activity in human DCs was investigated within the context of LPS-induced inflammatory responses.

We performed a prediction of miR-511-3p target genes using two independent miRNA databases, TargetScan 8.0 and Targetspy, and found PPARGC1A and PPARGC1B as putative targets, similar to studies by Tserel et al. [17]. In line with this, data presented in Figure 1 show that overexpression of miR-511-3p significantly downregulated PPAR $\gamma$ expression, as quantified by qRT-PCR. Recently, miRNAs have been shown to mediate pathways decreasing PPAR $\gamma$ expression during the onset of inflammation. For instance, miR-27b was shown to decrease PPAR $\gamma$ mRNA levels as mutation or deletion of the miR-27b start site completely abolished the reduction of luciferase activity in THP1 macrophages [38]. Additionally, they showed that miR-27b inhibitors prevented LPS-dependent PPAR $\gamma$ mRNA reduction in a concentration-dependent manner. It is noteworthy, however, that while our functional data corroborates changes in miR-511-3p expression level following inhibition or overexpression, the need for confirming PPAR $\gamma$ expression levels at the protein level is also crucial.

In line with previous reports, our data show that treatment of DCs with the PPAR $\gamma$ agonist rosiglitazone (RSG) induced PPAR $\gamma$ activity, whereas LPS treatment alone completely abrogates PPAR $\gamma$ activity (Figure 2). Two isoforms of PPAR $\gamma$ have been identified (PPAR $\gamma 1$ and 2), and studies show that both isoforms are downregulated in monocyte and macrophage cell lines following treatment with LPS [38]. However, prolonged exposure to LPS in these studies enabled recovery of PPAR $\gamma$ mRNA levels to almost basal levels after $24 \mathrm{~h}$ [38]. Notably, Samokhvalov et al. demonstrated that although LPS downregulates PPAR $\gamma$ activity, epoxyeicosatrienoic acids (EETs), which are biologically active metabolites of arachidonic acids, act as PPAR $\gamma$ agonists to suppress LPS-induced pro-inflammatory responses [39]. This could explain the increase in PPAR $\gamma$ activity following LPS/RSG treatment in miR-511-3p-inhibitor DCs seen in the present study (Figure 2A). Similarly, in a rat model of sepsis, infusion of low-dose LPS was shown to significantly decrease hepatic PPAR $\gamma$ protein levels, but administration of the LPS-binding agent (polymyxin B) reduced the plasma endotoxin level and prevented PPAR $\gamma$ downregulation in the septic animals [40], thus highlighting the complex mechanisms underlying the regulation of PPAR $\gamma$ during LPS-induced inflammation.

Several reports have indicated that induction of the IDO pathway of tryptophan metabolism contributes towards immune-modulatory events [41]. Within the context of inflammation, IDO induction leads to the suppression of T-cell effector responses [42]. A role for LPS in IDO induction has also been demonstrated by our group and others [20,43], which explains why IDO activity and expression is increased following LPS treatment. In this study, we show that LPS-induced IDO activity is significantly reduced in the presence of RSG compared to LPS alone. Interestingly, IDO activity following treatment with RSG and/or LPS in miR-511-3p-mimic DCs was also significantly reduced when compared to CT cells only. It is likely that transfection with miRNA mimics resulted in repression of other cell responses or miRNA target genes, as previously reported [44]. This could account for the decrease in IDO activity as well as IL-10 secretion in miR-511-3p-mimic cells. Recently, it has been demonstrated that fatty acid oxidisation by PPAR $\gamma$ in melanomas positively regulates IDO in DCs by promoting a switch towards a tolerogenic state to enable immune evasion [14]. In contrast, our data indicate that PPAR $\gamma$ activation negatively regulates IDO activity in DCs within the context of LPS-induced inflammation. A schematic representation of the relationship between miR-511-3p and PPAR $\gamma$ in modulating DC function is shown in Figure 6. 


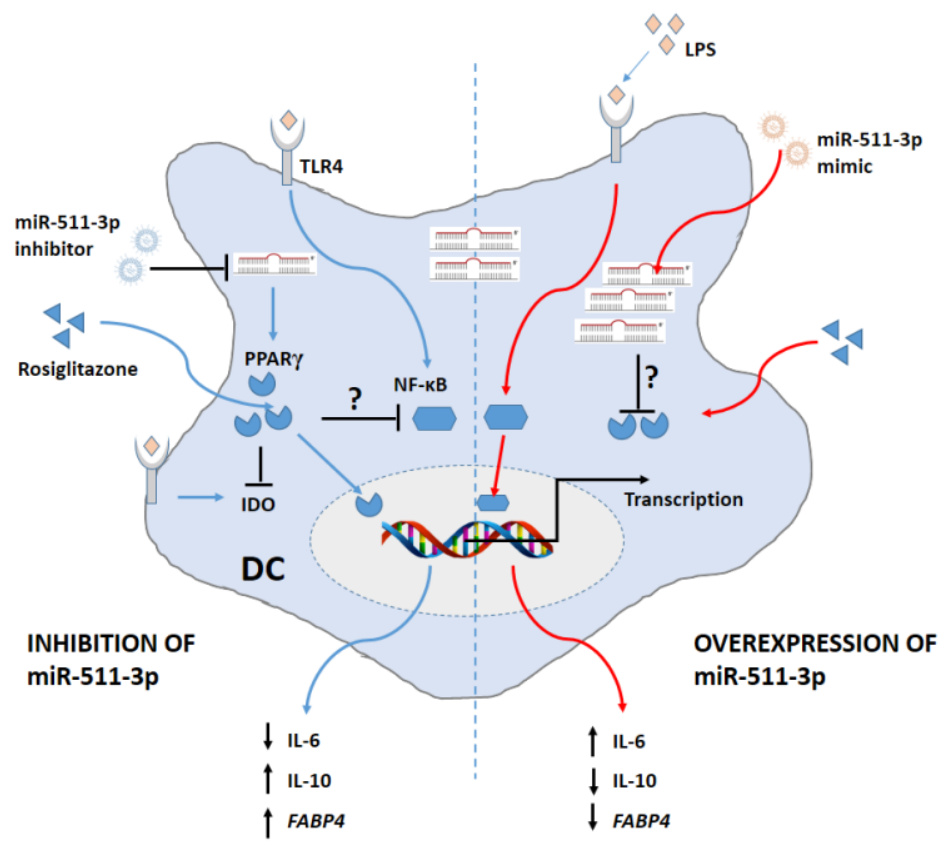

Figure 6. Schematic representation of the relationship between miR-511-3p and PPAR $\gamma$ in modulating human DC function. Downregulation of miR-511-3p promotes PPAR $\gamma$ expression and activity (FABP4) and subsequently suppresses LPS-induced inflammation. In contrast, overexpressing miR-511-3p reverses the effects of PPAR $\gamma$ and promotes transcription of pro-inflammatory genes.

The anti-inflammatory effect of PPAR $\gamma$ ligands in regulating immune responses is well documented. In particular, high dose 15d-PGJ2 or TZD (PPAR $\gamma$ agonists) treatment of monocytes and macrophages was shown to inhibit secretion of pro-inflammatory cytokines (IL-6, TNF- $\alpha$ and IL-1 $\beta$ ) [26] and suppress IFN- $\gamma$-dependent inducible genes [25,45]. Additionally, it has been shown that IL-10 is induced by RSG in experimental models of colitis and Parkinson's disease $[46,47]$. In the present study, we highlight the dynamics of IL-6 and IL-10 production by miR-511-3p-modified DCs, which further demonstrates the role of PPAR $\gamma$ supporting an anti-inflammatory profile in miR-511-3p-inhibitor DCs. Interestingly, a number of potential links between PPAR $\gamma$ and c-type lectins, particularly the mannose receptor (MR), have also been suggested. These include data showing that interaction between MR and Man-LAM from Mycobacterium tuberculosis can induce PPAR $\gamma$ activation [48]. Considering that changes in miR-511-3p expression are associated with changes in MR expression as well as IDO activity, as demonstrated previously [16], it is likely that miR-511-3p may play a role in regulating MR expression and DC function through $\operatorname{PPAR} \gamma$. These studies, therefore, suggest that PPAR $\gamma$ and signalling molecules/pathways controlling its expression or activity may serve as a target for anti-inflammatory therapy. In recent years, the therapeutic potential of microRNAs has been accumulating, particularly due to the development of small molecule analogues or inhibitors, which aim to suppress miRNA expression in human disease or block specific inflammatory pathways. However, clinical use of miRNA is dependent on the successful delivery of drugs to diseased organs. For instance, analogues of miR-511-3p in combination with other small molecule drugs could potentially block immune pathways that exacerbate inflammatory responses and enhance quality of life. Collectively, these data highlight the potential immune-regulatory role of miR-511-3p on PPAR $\gamma$ activity in human DCs. The roles of miRNAs and PPAR $\gamma$ in immune regulation are still being investigated, and this transcription factor is emerging as a key player in various stages of the resolution of inflammation.

Supplementary Materials: The following are available online at https: / www.mdpi.com/article / 10.3390/immuno2010008/s1, Figure S1: Apoptotic effect of miR-511-3p transfection on Mo-DCs. 
Figure S2: PPAR $\gamma$ activation by rosiglitazone (RSG) downregulates TNF- $\alpha$ production in human DC. Figure S3: IDO activity in untransfected DCs. Figure S4: Dendritic cell viability title.

Author Contributions: Conceptualisation, D.A. and A.M.G.; methodology, D.A., A.R., M.A. and C.M.; software, D.A. and A.R.; validation, D.A., A.R. and A.M.G.; formal analysis, D.A., A.R., M.A. and C.M.; investigation, D.A., A.R., M.A. and C.M.; resources, D.A. and A.M.G.; data curation, A.R., M.A. and C.M.; writing-original draft D.A., A.R. and A.M.G.; writing-review and editing, D.A., A.R., M.A., C.M. and A.M.G.; project administration, D.A. and A.M.G.; All authors have read and agreed to the published version of the manuscript.

Funding: D.A. is a recipient of the Vice Chancellor's Ph.D Scholarship at the University of Nottingham, United Kingdom.

Institutional Review Board Statement: The study was conducted according to the guidelines of the declaration of Helsinki, and the study was approved by the Research Ethics Committee, Faculty of Medicine and Health Sciences, University of Nottingham; BT08052013-160-1701.

Informed Consent Statement: Informed consent was obtained from all donors involved in the study.

Data Availability Statement: Not applicable.

Acknowledgments: Authors would like to acknowledge support from the flow cytometry facility (School of Life Sciences, University of Nottingham).

Conflicts of Interest: The authors have no competing interests to declare.

\section{References}

1. Rosenfeld, Y.; Shai, Y. Lipopolysaccharide (Endotoxin)-host defense antibacterial peptides interactions: Role in bacterial resistance and prevention of sepsis. Biochim. Biophys. Acta (BBA) Biomembr. 2006, 1758, 1513-1522. [CrossRef] [PubMed]

2. Gilroy, D.; Lawrence, T. The resolution of acute inflammation: A 'tipping point' in the development of chronic inflammatory diseases. In The Resolution of Inflammation; Rossi, A.G., Sawatzky, D.A., Eds.; Birkhäuser Basel: Basel, Switzerland, 2008; pp. 1-18.

3. Lawrence, T.; Fong, C. The resolution of inflammation: Anti-inflammatory roles for NF-кB. Int. J. Biochem. Cell Biol. 2010, 42, 519-523. [CrossRef]

4. Lawrence, T. The Nuclear Factor NF-кB Pathway in Inflammation. Cold Spring Harb. Perspect. Biol. 2009, 1, a001651. [CrossRef]

5. Ahmadian, M.; Suh, J.M.; Hah, N.; Liddle, C.; Atkins, A.R.; Downes, M.; Evans, R.M. PPARgamma signaling and metabolism: The good, the bad and the future. Nat. Med. 2013, 19, 557-566. [CrossRef]

6. Klotz, L.; Dani, I.; Edenhofer, F.; Nolden, L.; Evert, B.; Paul, B.; Kolanus, W.; Klockgether, T.; Knolle, P.; Diehl, L. Peroxisome proliferator-activated receptor gamma control of dendritic cell function contributes to development of CD4+ T cell anergy. J. Immunol. 2007, 178, 2122-2131. [CrossRef]

7. Nencioni, A.; Grunebach, F.; Zobywlaski, A.; Denzlinger, C.; Brugger, W.; Brossart, P. Dendritic cell immunogenicity is regulated by peroxisome proliferator-activated receptor gamma. J. Immunol. 2002, 169, 1228-1235. [CrossRef] [PubMed]

8. Angeli, V.; Hammad, H.; Staels, B.; Capron, M.; Lambrecht, B.N.; Trottein, F. Peroxisome proliferator-activated receptor gamma inhibits the migration of dendritic cells: Consequences for the immune response. J. Immunol. 2003, 170, 5295-5301. [CrossRef] [PubMed]

9. Faveeuw, C.; Fougeray, S.; Angeli, V.; Fontaine, J.; Chinetti, G.; Gosset, P.; Delerive, P.; Maliszewski, C.; Capron, M.; Staels, B.; et al. Peroxisome proliferator-activated receptor gamma activators inhibit interleukin-12 production in murine dendritic cells. FEBS Lett. 2000, 486, 261-266. [CrossRef]

10. Salazar, F.; Awuah, D.; Negm, O.H.; Shakib, F.; Ghaemmaghami, A.M. The role of indoleamine 2,3-dioxygenase-aryl hydrocarbon receptor pathway in the TLR4-induced tolerogenic phenotype in human DCs. Sci. Rep. 2017, 7, 43337. [CrossRef] [PubMed]

11. Fallarino, F.; Grohmann, U.; Vacca, C.; Bianchi, R.; Orabona, C.; Spreca, A.; Fioretti, M.C.; Puccetti, P. T cell apoptosis by tryptophan catabolism. Cell Death Differ. 2002, 9, 1069-1077. [CrossRef] [PubMed]

12. Tas, S.W.; Vervoordeldonk, M.J.; Hajji, N.; Schuitemaker, J.H.N.; van der Sluijs, K.F.; May, M.J.; Ghosh, S.; Kapsenberg, M.L.; Tak, P.P.; de Jong, E.C. Noncanonical NF- $\mathrm{kB}$ signaling in dendritic cells is required for indoleamine 2,3-dioxygenase (IDO) induction and immune regulation. Blood 2007, 110, 1540-1549. [CrossRef]

13. Mbongue, J.C.; Nicholas, D.A.; Torrez, T.W.; Kim, N.-S.; Firek, A.F.; Langridge, W.H.R. The Role of Indoleamine 2, 3-Dioxygenase in Immune Suppression and Autoimmunity. Vaccines 2015, 3, 703-729. [CrossRef]

14. Zhao, F.; Xiao, C.; Evans, K.S.; Theivanthiran, T.; DeVito, N.; Holtzhausen, A.; Liu, J.; Liu, X.; Boczkowski, D.; Nair, S.; et al. Paracrine Wnt5a- $\beta$-Catenin Signaling Triggers a Metabolic Program that Drives Dendritic Cell Tolerization. Immunity 2018, 48, 147-160.e147. [CrossRef] [PubMed]

15. Bentwich, I.; Avniel, A.; Karov, Y.; Aharonov, R.; Gilad, S.; Barad, O.; Barzilai, A.; Einat, P.; Einav, U.; Meiri, E.; et al. Identification of hundreds of conserved and nonconserved human microRNAs. Nat. Genet. 2005, 37, 766-770. [CrossRef] [PubMed] 
16. Awuah, D.; Alobaid, M.; Latif, A.; Salazar, F.; Emes, R.D.; Ghaemmaghami, A.M. The Cross-Talk between miR-511-3p and C-Type Lectin Receptors on Dendritic Cells Affects Dendritic Cell Function. J. Immunol. 2019, 203, 148-157. [CrossRef] [PubMed]

17. Tserel, L.; Runnel, T.; Kisand, K.; Pihlap, M.; Bakhoff, L.; Kolde, R.; Peterson, H.; Vilo, J.; Peterson, P.; Rebane, A. MicroRNA expression profiles of human blood monocyte-derived dendritic cells and macrophages reveal miR-511 as putative positive regulator of Toll-like receptor 4. J. Biol. Chem. 2011, 286, 26487-26495. [CrossRef]

18. Karo-Atar, D.; Itan, M.; Pasmanik-Chor, M.; Munitz, A. MicroRNA profiling reveals opposing expression patterns for miR-511 in alternatively and classically activated macrophages. J. Asthma Off. J. Assoc. Care Asthma 2015, 52, 545-553. [CrossRef] [PubMed]

19. Fleischmann, K.K.; Pagel, P.; von Frowein, J.; Magg, T.; Roscher, A.A.; Schmid, I. The leukemogenic fusion gene MLL-AF9 alters microRNA expression pattern and inhibits monoblastic differentiation via miR-511 repression. J. Exp. Clin. Cancer Res. 2016, 35, 9. [CrossRef]

20. Salazar, F.; Hall, L.; Negm, O.H.; Awuah, D.; Tighe, P.J.; Shakib, F.; Ghaemmaghami, A.M. The mannose receptor negatively modulates the Toll-like receptor 4-aryl hydrocarbon receptor-indoleamine 2,3-dioxygenase axis in dendritic cells affecting $\mathrm{T}$ helper cell polarization. J. Allergy Clin. Immunol. 2016, 137, 1841-1851 e1842. [CrossRef]

21. Garcia-Nieto, S.; Johal, R.K.; Shakesheff, K.M.; Emara, M.; Royer, P.J.; Chau, D.Y.; Shakib, F.; Ghaemmaghami, A.M. Laminin and fibronectin treatment leads to generation of dendritic cells with superior endocytic capacity. PLoS ONE 2010, 5, e10123. [CrossRef]

22. Aldajani, W.A.; Salazar, F.; Sewell, H.F.; Knox, A.; Ghaemmaghami, A.M. Expression and regulation of immune-modulatory enzyme indoleamine 2,3-dioxygenase (IDO) by human airway epithelial cells and its effect on T cell activation. Oncotarget 2016, 7, 57606-57617. [CrossRef]

23. Donaldson, A.R.; Tanase, C.E.; Awuah, D.; Vasanthi Bathrinarayanan, P.; Hall, L.; Nikkhah, M.; Khademhosseini, A.; Rose, F.; Alexander, C.; Ghaemmaghami, A.M. Photocrosslinkable Gelatin Hydrogels Modulate the Production of the Major Proinflammatory Cytokine, TNF- $\alpha$, by Human Mononuclear Cells. Front. Bioeng. Biotechnol. 2018, 6. [CrossRef] [PubMed]

24. Ghaemmaghami, A.M.; Shakib, F. Human T cells that have been conditioned by the proteolytic activity of the major dust mite allergen Der p 1 trigger enhanced immunoglobulin E synthesis by B cells. Clin. Exp. Allergy 2002, 32, 728-732. [CrossRef]

25. Ricote, M.; Li, A.C.; Willson, T.M.; Kelly, C.J.; Glass, C.K. The peroxisome proliferator-activated receptor-gamma is a negative regulator of macrophage activation. Nature 1998, 391, 79-82. [CrossRef] [PubMed]

26. Jiang, C.; Ting, A.T.; Seed, B. PPAR-gamma agonists inhibit production of monocyte inflammatory cytokines. Nature 1998, 391, 82-86. [CrossRef]

27. Szatmari, I.; Gogolak, P.; Im, J.S.; Dezso, B.; Rajnavolgyi, E.; Nagy, L. Activation of PPAR $\gamma$ Specifies a Dendritic Cell Subtype Capable of Enhanced Induction of iNKT Cell Expansion. Immunity 2004, 21, 95-106. [CrossRef]

28. Wang, D.; Shi, L.; Xin, W.; Xu, J.; Xu, J.; Li, Q.; Xu, Z.; Wang, J.; Wang, G.; Yao, W.; et al. Activation of PPAR $\gamma$ inhibits proinflammatory cytokines production by upregulation of miR-124 in vitro and in vivo. Biochem. Biophys. Res. Commun. 2017, 486, 726-731. [CrossRef]

29. Appel, S.; Mirakaj, V.; Bringmann, A.; Weck, M.M.; Grünebach, F.; Brossart, P. PPAR- $\gamma$ agonists inhibit toll-like receptor-mediated activation of dendritic cells via the MAP kinase and NF-kB pathways. Blood 2005, 106, 3888-3894. [CrossRef]

30. Asada, K.; Sasaki, S.; Suda, T.; Chida, K.; Nakamura, H. Antiinflammatory Roles of Peroxisome Proliferator-activated Receptor $\gamma$ in Human Alveolar Macrophages. Am. J. Respir. Crit. Care Med. 2004, 169, 195-200. [CrossRef] [PubMed]

31. Robinson, C.M.; Hale, P.T.; Carlin, J.M. The Role of IFN- $\gamma$ and TNF- $\alpha$-Responsive Regulatory Elements in the Synergistic Induction of Indoleamine Dioxygenase. J. Interferon Cytokine Res. Off. J. Int. Soc. Interferon Cytokine Res. 2005, 25, 20-30. [CrossRef]

32. Robinson, C.M.; Shirey, K.A.; Carlin, J.M. Synergistic transcriptional activation of indoleamine dioxygenase by IFN-gamma and tumor necrosis factor-alpha. J. Interferon Cytokine Res 2003, 23, 413-421. [CrossRef]

33. Fujigaki, S.; Saito, K.; Sekikawa, K.; Tone, S.; Takikawa, O.; Fujii, H.; Wada, H.; Noma, A.; Seishima, M. Lipopolysaccharide induction of indoleamine 2,3-dioxygenase is mediated dominantly by an IFN-gamma-independent mechanism. Eur. J. Immunol. 2001, 31, 2313-2318. [CrossRef]

34. Varga, T.; Nagy, L. Nuclear receptors, transcription factors linking lipid metabolism and immunity: The case of peroxisome proliferator-activated receptor gamma. Eur. J. Clin. Investig. 2008, 38, 695-707. [CrossRef]

35. Díaz-Delfín, J.; Morales, M.; Caelles, C. Hypoglycemic Action of Thiazolidinediones/Peroxisome Proliferator-Activated Receptor $\gamma$ by Inhibition of the c-Jun $\mathrm{NH}_{2}$-Terminal Kinase Pathway. Diabetes 2007, 56, 1865-1871. [CrossRef] [PubMed]

36. Landreth, G. Therapeutic use of agonists of the nuclear receptor PPARgamma in Alzheimer's disease. Curr. Alzheimer Res. 2007, 4, 159-164. [CrossRef] [PubMed]

37. Lewis, J.D.; Lichtenstein, G.R.; Deren, J.J.; Sands, B.E.; Hanauer, S.B.; Katz, J.A.; Lashner, B.; Present, D.H.; Chuai, S.; Ellenberg, J.H.; et al. Rosiglitazone for active ulcerative colitis: A randomized placebo-controlled trial. Gastroenterology 2008, 134, 688-695. [CrossRef]

38. Jennewein, C.; von Knethen, A.; Schmid, T.; Brüne, B. MicroRNA-27b Contributes to Lipopolysaccharide-mediated Peroxisome Proliferator-activated Receptor $\gamma$ (PPAR $\gamma$ ) mRNA Destabilization. J. Biol. Chem. 2010, 285, 11846-11853. [CrossRef] [PubMed]

39. Samokhvalov, V.; Vriend, J.; Jamieson, K.; Akhnokh, M.; Manne, R.; Falck, J.; Seubert, J. PPAR $\gamma$ signaling is required for mediating eets protective effects in neonatal cardiomyocytes exposed to LPS. Front. Pharmacol. 2014, 5. [CrossRef]

40. Zhou, M.; Wu, R.; Dong, W.; Jacob, A.; Wang, P. Endotoxin downregulates peroxisome proliferator-activated receptor- $\gamma$ via the increase in TNF- $\alpha$ release. Am. J. Physiol. Regul. Integr. Comp. Physiol. 2008, 294, R84-R92. [CrossRef] 
41. von Bubnoff, D.; Bieber, T. The indoleamine 2,3-dioxygenase (IDO) pathway controls allergy. Allergy 2012, 67, 718-725. [CrossRef] [PubMed]

42. Cole, J.E.; Astola, N.; Cribbs, A.P.; Goddard, M.E.; Park, I.; Green, P.; Davies, A.H.; Williams, R.O.; Feldmann, M.; Monaco, C. Indoleamine 2,3-dioxygenase- 1 is protective in atherosclerosis and its metabolites provide new opportunities for drug development. Proc. Natl. Acad. Sci. USA 2015, 112, 13033-13038. [CrossRef]

43. Curti, A.; Trabanelli, S.; Salvestrini, V.; Baccarani, M.; Lemoli, R.M. The role of indoleamine 2,3-dioxygenase in the induction of immune tolerance: Focus on hematology. Blood 2009, 113, 2394-2401. [CrossRef] [PubMed]

44. Jin, H.Y.; Gonzalez-Martin, A.; Miletic, A.V.; Lai, M.; Knight, S.; Sabouri-Ghomi, M.; Head, S.R.; Macauley, M.S.; Rickert, R.C.; Xiao, C. Transfection of microRNA Mimics Should Be Used with Caution. Front. Genet. 2015, 6, 340. [CrossRef] [PubMed]

45. Chawla, A.; Barak, Y.; Nagy, L.; Liao, D.; Tontonoz, P.; Evans, R.M. PPAR- $\gamma$ dependent and independent effects on macrophagegene expression in lipid metabolism and inflammation. Nat. Med. 2001, 7, 48. [CrossRef]

46. Celinski, K.; Dworzanski, T.; Korolczuk, A.; Piasecki, R.; Slomka, M.; Madro, A.; Fornal, R. Effects of peroxisome proliferatoractivated receptors-gamma ligands on dextran sodium sulphate-induced colitis in rats. J. Physiol. Pharmacol. Off. J. Pol. Physiol. Soc. 2011, 62, 347-356.

47. Pisanu, A.; Lecca, D.; Mulas, G.; Wardas, J.; Simbula, G.; Spiga, S.; Carta, A.R. Dynamic changes in pro- and anti-inflammatory cytokines in microglia after PPAR-gamma agonist neuroprotective treatment in the MPTPp mouse model of progressive Parkinson's disease. Neurobiol. Dis. 2014, 71, 280-291. [CrossRef]

48. Rajaram, M.V.; Brooks, M.N.; Morris, J.D.; Torrelles, J.B.; Azad, A.K.; Schlesinger, L.S. Mycobacterium tuberculosis activates human macrophage peroxisome proliferator-activated receptor gamma linking mannose receptor recognition to regulation of immune responses. J. Immunol. 2010, 185, 929-942. [CrossRef] 